\title{
Estimation of dry matter yield of silage maize by means of multispectral aerial photography
}

\author{
J. G. P. W. CLEVERS 1 \& L. SIBMA²
}

1 Department of Landsurveying and Remote Sensing, Wageningen Agricultural University, P.O. Box 339, NL 6700 AH Wageningen, Netherlands

2 Centre for Agrobiological Research, P.O. Box 14, NL 6700 AA Wageningen, Netherlands

Received 19 January 1990; accepted 28 May 1990

\begin{abstract}
The increasing hectareage and trade of silage maize in the Netherlands and surrounding countries emphasizes the need for an objective and reliable procedure for assessing dry matter yield. The near-infrared reflectance factor of a crop, estimated by means of remote sensing techniques, may be used as an objective estimator of leaf area index. In this research it is shown that after proper calibration, dry matter yield may be estimated from aerial photographs taken at flowering stage. By analysing a calibration set, a regression function of dry matter yield on near-infrared reflectance factor was established. This regression function was subsequently used as a calibration curve for estimating dry matter yield of maize grown under similar conditions and recorded at the same day. Possibilities are discussed to establish a procedure for estimating and predicting silage maize yield incorporating remotely-sensed information.
\end{abstract}

Keywords: remote sensing, multispectral aerial photography, Zea mays L., yield estimation

\section{Introduction}

Silage maize in the Netherlands is grown by farmers to be sold as food for cattle breeding. As yield assessments are difficult and often subjective there is a need for an objective and reliable procedure for estimating dry matter (DM) yield of maize fields (preferably even a pre-harvest estimation).

Bunnik (1978) described the possibilities of applying optical remote sensing in agriculture, particularly with regard to its relation with crop characteristics such as coverage, leaf area index (LAI, defined as the total one-sided green leaf area per unit soil area) and biomass (fresh or dry matter weight of the above-ground plant parts). There is consensus that the near-infrared (NIR) reflectance factor may be most suitable for estimation of LAI or biomass (Colwell, 1983; Clevers, 1986). In the NIR region $(700-1300 \mathrm{~nm})$ of the electromagnetic spectrum, reflectance and transmittance of a green leaf are each about $50 \%$, and there is hardly any infrared absorption by a green leaf (Colwell, 1983). As a result, leaf layers underneath the upper layer (and soil underneath it) contribute significantly to the total measured 
NIR reflectance. As a result, the NIR reflectance factor is a suitable estimator of LAI (up to LAI values of 6 to 8). LAI, on its turn, will be correlated to total biomass. Consequently, yield of crops may also be estimated by the NIR reflectance factor (Aase et al., 1984; Pinter et al., 1981; Tucker et al., 1980), especially in the case of maize since the whole crop is harvested.

The objective of this study was to investigate the possibilities of remote sensing for estimating above-ground DM ( $=$ dry matter in $\mathrm{kg} \mathrm{ha}^{-1}$ ) yield of maize. A case study was performed for one particular field experiment by using linear regression of DM yield on the NIR reflectance factor obtained by means of aerial photography. Ultimately, remote sensing may be used as an objective and reliable procedure for estimating DM yield of maize over larger areas.

\section{Materials and methods}

\section{Field experiment}

Since 1979, nine cropping systems of grass, lucerne and maize with four nitrogen levels each (split-plot design in four replicates) were studied at the Ir A. P. Minderhoudhoeve, the experimental farm of the Wageningen Agricultural University, which is located in East-Flevoland on a homogeneous loamy (top)soil. In 1983, maize was sown as a test crop for studying the residual effects on DM yields and nitrogen uptake of 1-, 2- and 3-year crops of grass, lucerne and maize. In 1983, nitrogen fertilizer was applied only to the M1 treatment (continuous maize and arable crops as preceding crops) in quantities of $0,75,150$ and $225 \mathrm{~kg} \mathrm{ha}^{-1}$. Estimated LAI's ranged between 2 and 5 at flowering. For assessment of the residual effects, all 144 plots of $30 \mathrm{~m}^{2}(10 \mathrm{~m} \times 3 \mathrm{~m})$ each were harvested on 21 October 1983 . DM yields ranged between 8.0 and $14.8 \mathrm{t} \mathrm{ha}^{-1}$ and nitrogen uptake between 72 and $176 \mathrm{~kg} \mathrm{ha}^{-1}$ (treatment mean values). An extensive description of the lay-out and results of the field experiment is given by Sibma \& Spiertz (1986) and Spiertz \& Sibma (1986).

\section{Aerial photography}

Clevers $(1986,1988 a, 1988 b)$ has shown that multispectral aerial photography (MSP) is an appropriate technique for the frequent acquirement of remotely-sensed data in field experiments. Black and white photography was carried out by taking vertical photographs from a height of $800 \mathrm{~m}$. In order to match a NIR band, Kodak Infrared Aerographic Film 2424 was used in combination with a Wratten 87C filter. This resulted in an $840-900 \mathrm{~nm}$ spectral band. Development of the films was standardized and checked by means of sensitometry. The mission of 8 August 1983, carried out one week after flowering (anthesis) at maximal LAI and under clear sky conditions, was considered to be the most suitable for use in this study since it was closest to harvest (no flights were performed after 8 August in 1983).

Densities on the film negatives were measured by means of an automatized Macbeth TD-504 densitometer with a circular aperture of $0.25 \mathrm{~mm}$. At a scale of 1:8000 
this coincides with a spot of a diameter of $2 \mathrm{~m}$ in the field. The measuring procedure has been described by Clevers $(1986,1988 \mathrm{a})$. After converting the densities to radiant energy values by means of the characteristic curve, compensation for light falloff was made. A linear relationship between this corrected radiant energy value and the reflectance factor of the object was found. Reference targets with known reflectance characteristics were set up in the field during the mission and recorded at the same camera setting and under the same atmospheric conditions as the field experiment, in order to estimate the regression parameters. After this procedure of camera calibration and atmospheric correction, a mean NIR reflectance factor for each plot was calculated.

\section{Data analysis}

Linear regression of DM yield on the NIR reflectance factor was performed for a subset (training set), resulting in a calibration curve for this specific data set. Subsequently, this calibration curve was used for estimating DM yield of the remaining part of the experiment. This strategy of yield estimation is elucidated in Figure 1.

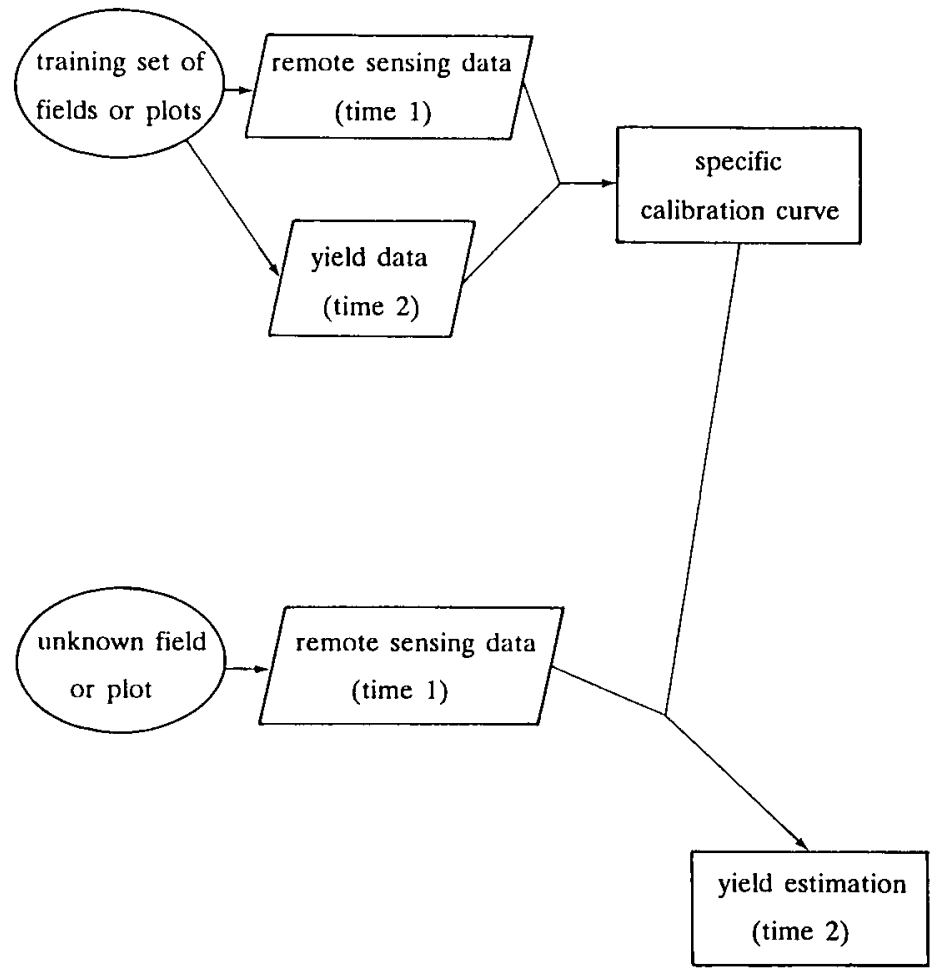

Fig. 1. Flow diagram, illustrating the yield estimation strategy in this research. 


\section{Results}

\section{Analysis of variance}

Means, estimated coefficients of variation (CV) of residuals of individual plots and critical levels in testing for treatment effects, for the DM yield at the end of the growing season and for the measured NIR reflectance factor on 8 August 1983 are listed in Table 1. The pooled error variance was determined by means of appropriate averaging of inter-plot and intra-plot variances. The $\mathrm{CV}$ is the ratio of the square root of the mean squares of residuals and the mean value of the dependent variable. The critical level (often called $P$-value) is the smallest level of significance at which the observed result would just lead to rejection of the null hypothesis (that is a treatment has no effects).

All treatment effects were significant for DM yield and NIR reflectance factor. Hence the NIR reflectance factor is suitable for obtaining information on DM yield in this experiment. The CV value for the NIR reflectance cannot be compared directly to the one for DM yield due to the presence of an offset in the reflectance data (soil reflectance). Comparison of $\mathrm{CV}$ values is possible through the estimated DM yield (no offset).

\section{Regression of DM yield on NIR reflectance}

As described before, only the M1 treatment received nitrogen dressing in 1983 . This treatment yielded a range in DM yields that encompassed the total range by all nine treatments (Spiertz \& Sibma, 1986). Figure 2 shows that the regression of DM yield on NIR reflectance factor for all 16 plots of the M1 treatment was described satisfactorily by a linear function. This linear function was used as a calibration curve for this specific data set.

By using this calibration curve, DM yields were estimated for the 8 other cropping systems and compared with measured DM yields (Fig. 3). The scatter around the $45^{\circ}$ line is small $\left(\mathrm{CV}=0.057, R^{2}=0.854\right)$, but it still means a maximum deviation of about $1500 \mathrm{~kg} \mathrm{ha}^{-1}$ (twice the standard deviation) between actual and estimated yield. This variation is comparable to the residual variation within the yield data themselves (cf. Table 1).

Table 1. Measured dry matter (DM) yield, near-infrared (NIR) reflectance and estimated DM yield by reflectance measurements: mean, $\mathrm{CV}$ and critical level in testing for treatment effects.

\begin{tabular}{lcclll}
\hline & Mean & CV & \multicolumn{2}{l}{ Critical level in testing } \\
\cline { 3 - 5 } & & & interaction & $\begin{array}{l}\text { cropping } \\
\text { system }\end{array}$ & $\begin{array}{l}\text { nitrogen } \\
\text { nutrition }\end{array}$ \\
DM yield (kg ha-1) & 12611 & 0.062 & $<0.001$ & $<0.001$ & $<0.001$ \\
NIR reflectance (\%) & 47.4 & 0.020 & $<0.001$ & $<0.001$ & $<0.001$ \\
Estimated DM yield $\left(\mathrm{kg} \mathrm{ha}^{-1}\right)$ & 12681 & 0.060 & $<0.001$ & $<0.001$ & $<0.001$ \\
\hline
\end{tabular}




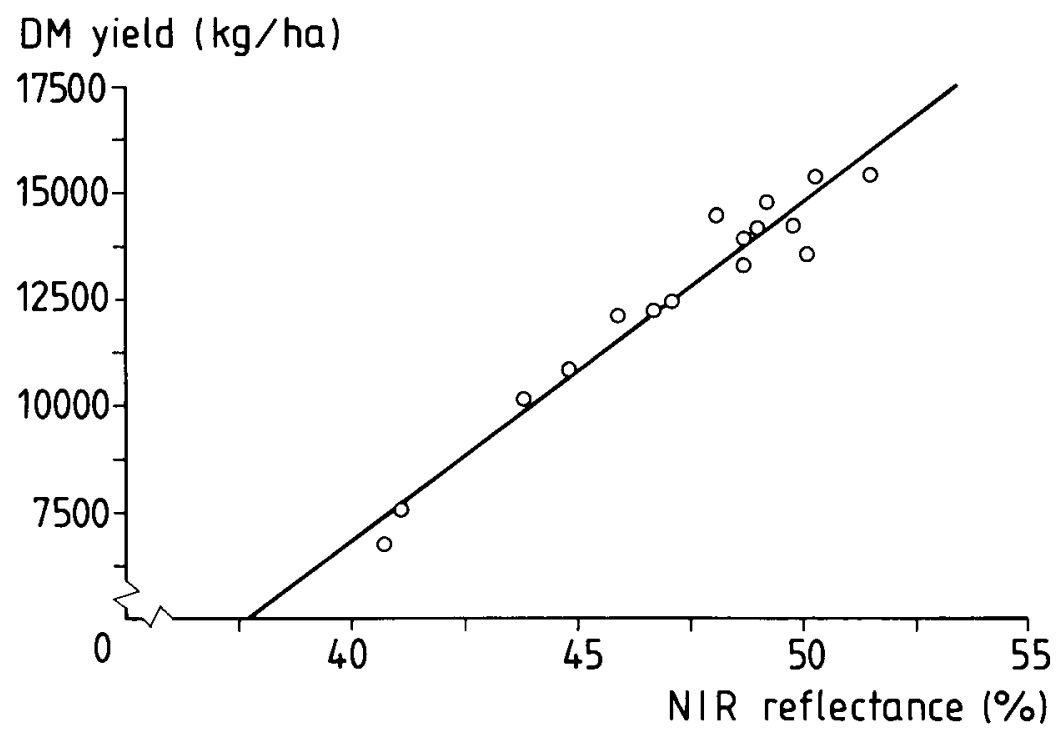

Fig. 2. Regression of dry matter (DM) yield on near-infrared (NIR) reflectance factor for the M1 treatments in 1983: DM $=-24.9+0.792 \times \mathrm{NIR}(r=0.974, \mathrm{CV}=0.049)$.

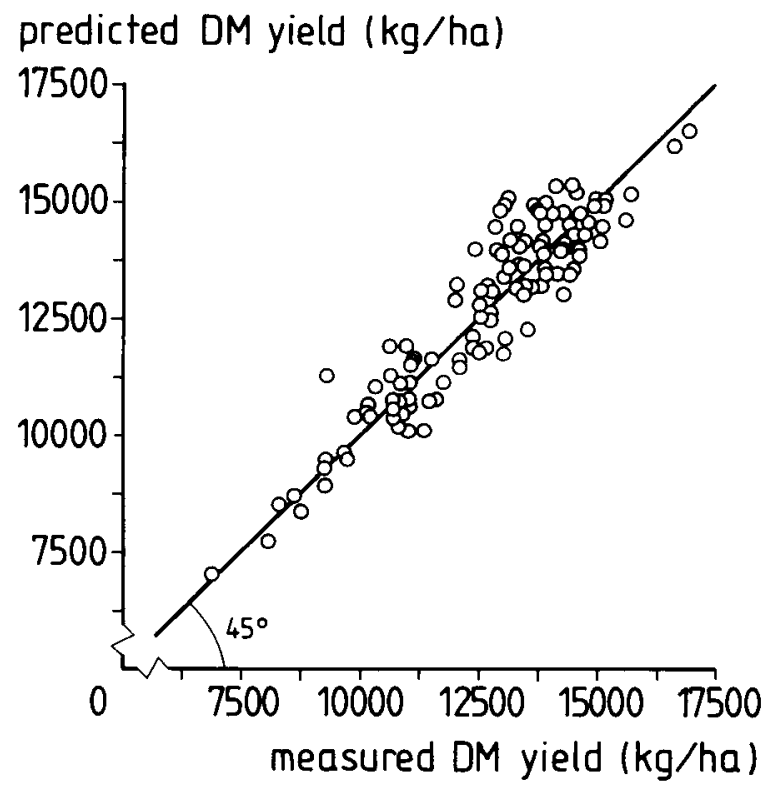

Fig. 3. Estimated DM yield as a function of measured DM yield for the maize crop in 1983 (remaining 8 cropping systems). 
If an analysis of variance is performed on the estimated DM yield data by using the linear function of Figure 2 for all nine treatments, the results are equal to the results of the yield measured in the field (Table 1).

\section{Discussion}

It was shown that, after proper calibration, DM yield of maize may be estimated by using information from aerial photography. A regression function was derived describing the relationship between DM yield at final harvest and the NIR reflectance factor at flowering, which relationship offered an accurate estimation of the observed yields. The study described in this paper was restricted to a single field experiment, on a single location in a single year. If yields over a larger region are considered, then the relationship will be worse due to the diversity in error sources with regard to the growth rate between recording and harvest, such as drought effects differing from location to location. Moreover, it is not expected that the presented calibration curve will be universally valid. Many factors may influence the relationship, such as recording date, cultivar, soil and weather conditions.

Possible procedures of using the NIR reflectance (or remote sensing information in general) for yield prediction of maize are the following:

a. Using selected plots to establish a calibration curve, similar to Figure 2, by harvesting these plots a few weeks before, but as close as possible to the final harvest date. Total DM normally does not change substantially at the end of the season. Further research has to show if year to year variations in the calibration curve are small enough to generalize the relationship.

b. Initializing or updating a crop growth model to obtain yield predictions (Maas, 1988). In such a model, crop growth is simulated in dependence on weather conditions, cultivation data (sowing date, cultivar) and soil information (e.g., in order to take drought effects into account). Based on remote sensing information, such a model might be initialized or model estimations during the growing season might be adjusted for each individual field.

It may be concluded that remote sensing offers possibilities for estimating and predicting yield of silage maize for individual fields.

\section{Acknowledgements}

The authors are indebted to Dr S. C. van de Geijn and Dr C. J. T. Spitters for their useful suggestions and valuable comments on the manuscript.

\section{References}

Aase, J. K., F. H. Siddoway \& J. P. Millard, 1984. Spring wheat-leaf phytomass and yield estimates from airborne scanner and hand-held radiometer measurements. International Journal of Remote Sensing 5: 771-781.

Bunnik, N. J. J., 1978. The multispectral reflectance of shortwave radiation by agricultural crops in relation with their morphological and optical properties. Doctoral Thesis, Mededelingen Landbouwhogeschool Wageningen $78-1,175 \mathrm{pp}$. 
Clevers, J. G. P. W., 1986. Application of remote sensing to agricultural field trials. Doctoral Thesis, Wageningen Agricultural University Papers 86-4, 227 pp.

Clevers, J. G. P. W., 1988a. Multispectral aerial photography as a new method in agricultural field trial analysis. International Journal of Remote Sensing 9: 319-332.

Clevers, J. G. P. W., 1988b. Multispectral aerial photography as a supplemental technique in agricultural research. Netherlands Journal of Agricultural Science 36: 75-90.

Colwell, R. N. (Ed.), 1983. Manual of remote sensing. Volume 1. Second edition. American Society of Photogrammetry, Falls Church, Virginia, 1232 pp.

Maas, S. J., 1988. Use of remotely-sensed information in agricultural crop growth models. Ecological Modelling 41: 247-268.

Pinter, P. J. Jr., R. D. Jackson, S. B. Idso \& R. D. Reginato, 1981. Multidate spectral reflectance as predictors of yield in water stressed wheat and barley. International Journal of Remote Sensing 2 : 43-48.

Sibma, L. \& H. J. Spiertz, 1986. Dry matter production and nitrogen utilization in cropping systems with grass, lucerne and maize. 1. Comparison of crop characteristics, growth and production. Netherlands Journal of Agricultural Science 34: 25-35.

Spiertz, H. J. \& L. Sibma, 1986. Dry matter production and nitrogen utilization in cropping systems with grass, lucerne and maize. 2. Nitrogen yield and utilization. Netherlands Journal of Agricultural Science 34: 37-47.

Tucker, C. J., B. N. Holben, J. H. Elgin Jr. \& J. E. McMurtrey, 1980. Relationship of spectral data to grain yield variation. Photogrammetric Engineering and Remote Sensing 46: 657-666. 